\title{
THE EXCRETION OF COPROPORPHYRIN I FOLLOWING HEMOR- RHAGE IN DOGS
}

\author{
BY K. DOBRINER AND C. P. RHOADS
}

(From the Hospital of The Rockefeller Institute for Medical Research, New York City)

The studies of Dobriner and his coworkers $(1,2,3,4)$ present evidence which suggests that coproporphyrin $I$ is a by-product in the synthesis of the Type III porphyrin which is to go on to the formation of the respiratory pigments. Furthermore, they advance much evidence in favor of the view that coproporphyrin $I$ is formed under normal conditions at a rate which is constantly proportional to the rate of formation of the Type III porphyrin compounds. The objection has been advanced, however, that the published experiments are not convincing, since they all involve either a pathological state such as hemolytic jaundice, or they employ a hemolytic drug such as phenylhydrazine. Since destruction of erythrocytes is a feature in both of these experiments, a theoretically possible synthesis of Type I coproporphyrin which may be formed in increased amounts from breakdown products of the Type III porphyrin of the respiratory pigments cannot be excluded positively. No evidence exists, however, to suggest that such a conversion occurs in nature.

To overcome these objections, the simple experiment has been made of measuring quantitatively the rate of excretion of coproporphyrin I in normal dogs during control periods and then during periods of increased hematopoietic activity following anemia due to the removal of blood. In this way any possibility of the resynthesis of the products of the breakdown of Type III porphyrins to those of Type I structure is avoided.

\section{METHODS}

Healthy mongrel dogs were kept in metabolism cages, and all the urine and stools were collected daily with toluol as a preservative. The diet was made absolutely uniform by feeding each animal exactly 2 pounds of a stock commercial dog food daily. All of the diet was eaten. The animals were bled from the jugular vein, 50 cc. daily, for 20 days. Blood volumes were determined by the vital red method. Reticulocyte counts were made on smears of blood vitally stained with brilliant cresyl blue. Each dog received $50 \mathrm{mgm}$. daily of iron ammonium citrate injected intramuscularly to insure an adequate reserve of iron.
The methods for the qualitative and quantitative measurements of the excreted coproporphyrin I were those which have been described by Dobriner and coworkers (1). Aliquots of the total urine and feces excreted in 5-day periods were analyzed for control periods of 30 days and for periods of hemorrhage of 30 days. It should be emphasized that single determinations or studie? over brief periods are valueless in investigations of this kind.

\section{RESULTS}

Experiment I (Figures 1 and 2). An average total excretion of coproporphyrin I of 32 micrograms daily for a control period of 30 days was observed. The values were remarkably constant. In the first 5-day period following bleeding the total circulating hemoglobin decreased from 148 to 109 grams, $100 \mathrm{cc}$. of blood with an $\mathrm{O}_{2}$ combining capacity of 19.6 volumes per cent being calculated as 13.8 grams. A moderate increase in the number of circulating reticulocytes appeared, but the excreted coproporphyrin I increased from 37 to 67 micrograms daily. As the bleeding continued, the circulating reticulocytes rose to 8 per cent and the excretion of coproporphyrin I to 230

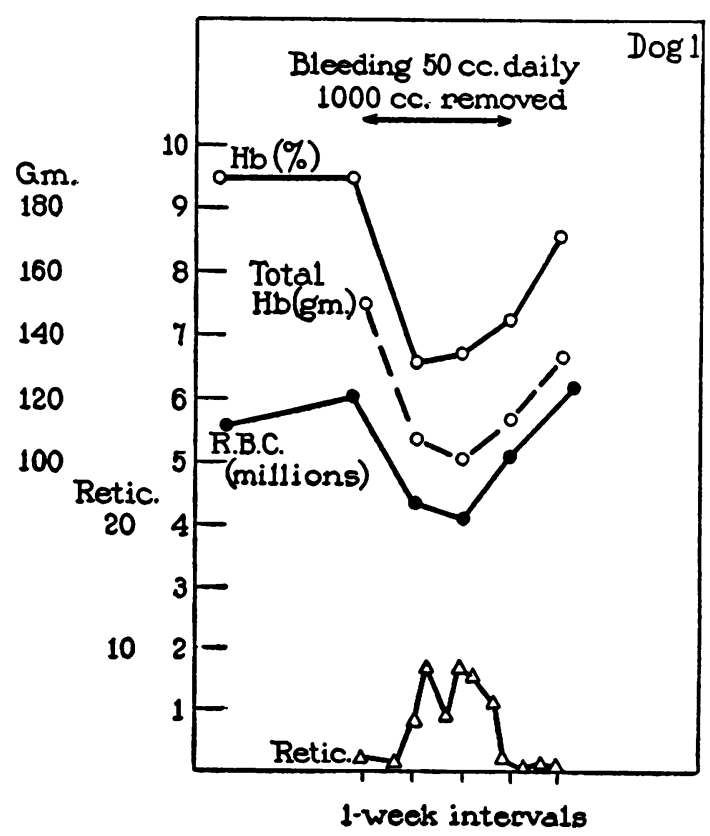

Fig. 1. Levels of Blood during Experiment I 


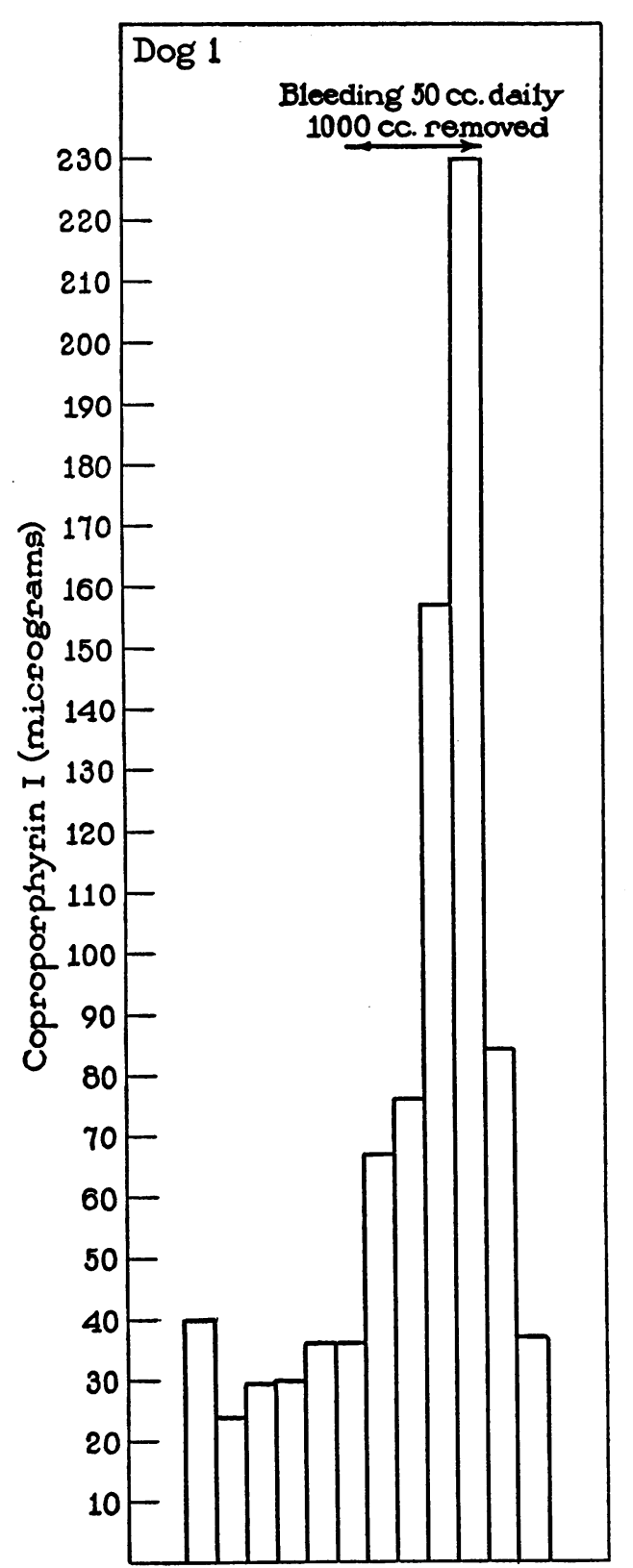

Fig. 2. Average Daily Total Excretion of CoproPORPHYrIN I IN MICROGRAMS FOR 5-DAY PERIODS IN THE Course of Experiment I

micrograms daily-5 times the original level. This was coincidental with an increase of the total circulating hemoglobin from 102 to 116 grams in spite of continued bleeding. After the bleeding was stopped, the coproporphyrin decreased again to 37 micrograms daily as normal blood levels were approached and the stimulus to hematopoiesis became less.

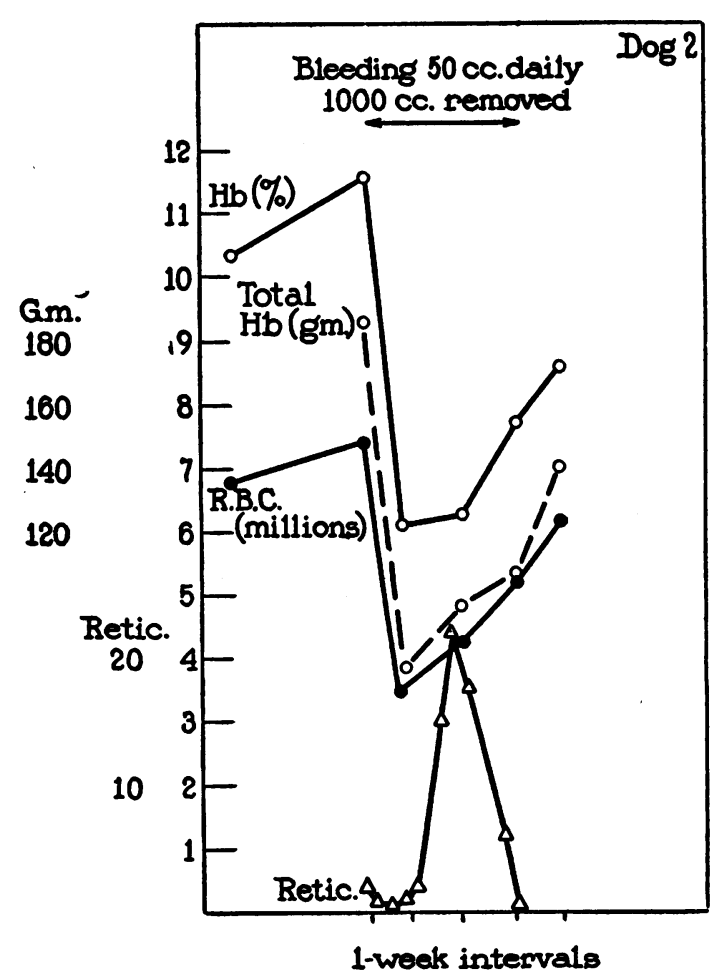

Fig. 3. Levers of Blood during Experiment II

Experiment II (Figures 3 and 4). In this experiment there was an average total excretion of coproporphyrin I of 42 micrograms daily during the control period of 30 days. In the first 5-day period of bleeding the total circulating hemoglobin decreased from 183 to 78 grams. An immediate increase in the excretion of coproporphyrin I resulted-from 42 to 90 micrograms daily-and this was immediately reflected in an increase of the number of circulating reticulocytes to 20 per cent. In the next 10 days a slight decrease in the rate of excretion of coproporphyrin I apparently reflected an abscess at the site of injection of iron. As this was drained, however, the daily output of coproporphyrin I increased to 120 micrograms as regeneration of blood became more active as shown by a rising total hemoglobin-from 78 to 105 grams-in the face of continued hemorrhage. After the bleeding was stopped, however, the daily excretion of coproporphyrin I promptly dropped to 88 micrograms, reflecting the lessened rate of hematopoiesis.

\section{DISCUSSION}

From the facts it is clear that bleeding in dogs results in a very marked increase in the rate of 


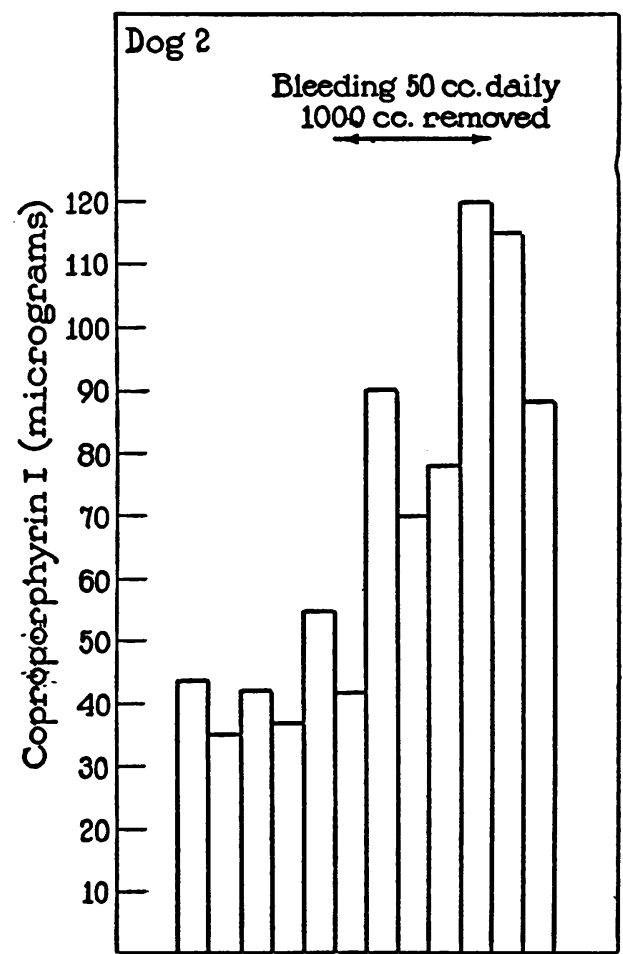

Fig. 4. Average Daily Total Excretion of CoproPORPhyrin I IN Micrograms for 5-day Periods in the COURSE OF EXPERIMENT II

excretion of coproporphyrin I. This increase is most marked when regeneration of hemoglobin is most active as shown by the increase of total circulating hemoglobin in spite of continued bleeding. Following the cessation of bleeding and the restoration of levels of blood which are within the normal range the rate of excretion of coproporphyrin I decreases again. Since the hemoglobin of the removed blood is no longer available for metabolism, its content of Type III porphyrin cannot serve as a source for the excreted Type I compound. The striking parallelism between the rate of formation of new Type III porphyrin as hemoglobin and the rate of excretion of Type I coproporphyrin suggests that the latter is constructed in the course of synthesis of the Type III compounds in the respiratory pigment and is excreted as a by-product of this synthesis. It suggests, furthermore, that the rate of excretion of Type I coproporphyrin is an index of the activity of the bone marrow in hematopoiesis.

The sharp discrepancy between the amount of coproporphyrin I excreted during the periods of bleeding in Experiments I and II is of considerable interest. In Experiment $I$ an increase of 1800 micrograms of porphyrin over the control period of the same length reflects a very active regeneration with prompt restoration of normal levels of the blood. In Experiment II, on the other hand, the increase of excreted coproporphyrin was much less- 600 micrograms-and the rate of replacement of hemoglobin was correspondingly slow, a fact due possibly to the intercurrent infection.

No conclusions can be drawn from these experiments concerning the quantitative relationship between the grams of hemoglobin produced and the micrograms of coproporphyrin I excreted. The available methods are too rough to allow of fine analysis. Furthermore, the probability of an enterohepatic circulation of porphyrin similar to that of urobilin introduces a factor which cannot be controlled.

TABLE I

Levels of blood during Experiments I and II

\begin{tabular}{l|c|c|c|c|c|c|c}
\hline \hline Date & $\begin{array}{c}\text { Red } \\
\text { blood } \\
\text { cells }\end{array}$ & $\begin{array}{c}\text { He- } \\
\text { mo- } \\
\text { globin }\end{array}$ & $\begin{array}{c}\text { He- } \\
\text { mato- } \\
\text { crit }\end{array}$ & $\begin{array}{c}\text { Plas- } \\
\text { ma } \\
\text { vol- } \\
\text { ume }\end{array}$ & $\begin{array}{c}\text { Blood } \\
\text { vol- } \\
\text { ume }\end{array}$ & $\begin{array}{c}\text { Total } \\
\text { hemo- } \\
\text { globin }\end{array}$ & Weight \\
\hline $\begin{array}{c}\text { millions } \\
\text { per cu. } \\
\text { mm. }\end{array}$ & $\begin{array}{c}\text { per } \\
\text { cent }\end{array}$ & & $c c$. & $c c$. & grams & kgm. \\
\hline
\end{tabular}

EXPERIMENT I

\begin{tabular}{l|l|l|l|l|l|l|l}
\hline September 9 .. & 6.02 & 95 & 430 & 643 & 1130 & 148 & 11.75 \\
\hline
\end{tabular}

Bleeding begun 50 cc. daily

\begin{tabular}{l|l|l|l|l|l|l|l}
\hline September 16 & 4.43 & 66 & 372 & 760 & 1220 & 111 & 11.75 \\
September 24 & 4.29 & 67 & 325 & 740 & 1100 & 102 & 12.0 \\
October 1..... & 5.19 & 73 & 326 & 800 & 1200 & 120 & 11.75 \\
\hline
\end{tabular}

Bleeding stopped $1000 \mathrm{cc}$. removed

\begin{tabular}{l|l|l|l|l|l|l|l|}
\hline October $8 \ldots . .$. & 6.21 & 86 & 406 & 660 & 1110 & 132 & 11.6 \\
\hline
\end{tabular}

EXPERIMENT II

\begin{tabular}{l|r|r|r|r|r|r|l}
\hline September 9 .. & 7.47 & 116 & 527 & 540 & 1140 & 183 & 11.5 \\
\hline \multicolumn{7}{c}{ Bleeding begun 50 cc. daily } \\
\hline September 16 & 3.50 & 61 & 277 & 660 & 910 & 76 & 11.25 \\
September 24 & 4.17 & 63 & 322 & 745 & 1100 & 96 & 10.25 \\
October 1..... & 5.29 & 77 & 355 & 640 & 990 & 105 & 10.1 \\
\hline
\end{tabular}

Bleeding stopped 1000 cc. removed

\begin{tabular}{l|l|l|l|l|l|l|l}
\hline October 8.... & 6.92 & 92 & 481 & 570 & 1100 & 140 & 9.9
\end{tabular}




\section{CONCLUSIONS}

1. In the dog, bleeding results in an increase in the rate of excretion of coproporphyrin Type $I$.

2. The rate of excretion of coproporphyrin I varies with the rate of formation of Type III porphyrin as new hemoglobin.

3. Coproporphyrin Type I is probably a byproduct in the synthesis of the Type III porphyrin compounds.

4. The rate of excretion of coproporphyrin I is probably an index of hematopoietic activity under normal conditions.

\section{BIBLIOGRAPHY}

1. Dobriner, Konrad, Porphyrin excretion in the feces in normal and pathological conditions. J. Biol. Chem., 1937, 120, 115.

2. Dobriner, Konrad, Excretion of porphyrin by dogs. Proc. Soc. Exper. Biol. and Med., 1937, 36, 757.

3. Dobriner, K., Strain, W. H., and Localio, S. A., I. Quantitative measurement of coproporphyrin and total coproporphyrin I excretion in normals. Proc. Soc. Exper. Biol. and Med., 1937 36, 752.

4. Dobriner, K., Strain, W. H., Localio, S. A., Keutmann, H., and Stephens, D. I., II. Coproporphyrin I metabolism and hematopoietic activity. Proc. Soc. Exper. Biol. and Med., 1937, 36, 755. 